\title{
DE DE GRUYTER OPEN

\section{AN ORGANISATIONAL STUDY ON THE EFFECTS OF INTRINSIC CUSTOMER SERVICE DEMANDS: A PERSPECTIVE FROM EMOTIONAL LABOUR THEORY}

\author{
BABATUNDE Akanji \\ Department of Human Resource Management, Elizade University, Nigeria
}

\begin{abstract}
:
The purpose of this research is to examine employees' views on adverse consequences caused by strict compliance to display rules of intrinsic labour demands as against its appropriate necessities within a call centre context. Using an interpretative phenomenological methodology for the study analysis, 25 semi-structured interviews were conducted with telephone agents working in a call centre outlet in Lagos state, Nigeria. Based on the emotional labour theory, enquires were made about general outcomes experienced from conforming to organisational rules of emotional management during customer service encounters. Findings confirmed that the adversarial impact of affective conformity tends to threaten the positive intentions of these mandatory components of service work. Thus, a proposed theoretical model emerged from the study's interpretive accounts Based on these significant research findings, detailed practical implications were discussed on ways in which call centre businesses operating in a non-Western context can extenuate poor affective deliveries arising from mismanagement of emotional labour.
\end{abstract}

Key words: Emotional labour, Call-centres outlets, Nigeria, non-Western context, telephone agents

\section{Introduction}

One of the high demands of call centre work is that telephone advisors are mainly involved in emotional labour which should impact positively on customer satisfaction and create repurchase intentions (Lam \& Chen, 2012). While there are large numbers of conceptual reports and empirical studies on call centre emotional labour realities in developed countries, there appears to be a lower representation of knowledge of similar studies in developing countries despite the fruitful development of call centre stations in these regions (Mahesh \& Kasturi, 2006). Consequently, the importance of addressing customer service working conditions in third world countries 
is because these nations have proved to yield huge economic benefits to large companies from industrialised economies outsourcing their call centre operations and engaging in off-shore customer service activities in these low income countries like India, Pakistan, Malaysia and other Asian countries (Das, Dhawadkar, \& Brandes, 2008).

Shifting focus to Africa, Nigeria is recognized as a major market for telecommunications equipment and services (Adebisi, 2011). Known as one of the most populous nations in Africa, the country always had what it takes to attract the attention of global ICT investors (Pyramid Research, 2010). Apparently a vast number of emotional labour studies assessing the consequences of the regulatory practices surrounding affective deliveries still stems from call centre samples in advanced countries. But Jaarsveld and Poster, (2013, p. 167) suggested that researchers should utilise this mainstream contexts to investigate whether "emotional labour processes operates in the same way for the offshore workforce...as it does for call centre samples in advanced economies". This will create a wealth of knowledge on how emotional labour experiences may be perceived and practiced in countries of a different cultural orientation from that of Western nations.

Against this backdrop, the objectives of this study are in three-fold. The first objective is to make valuable contributions to global call centre literature by disseminating novel research information about how Nigerian service employees conceptualise emotional labour service prescribed for dealing with customers over the phone. The second objective is to assess accounts of the inimical outcomes of emotional labour that may undermine its desired implications. The final objective is to provide practical implications for the call centre industry on strategies that can be introduced to enhance positive experiences of emotion work in this context.

\section{Literature review}

Morris and Feldman (1996, p. 987) defined emotional labour as "effort, planning, and control required to display organisationally desired emotions during interpersonal transaction". The concept was first conceived by Hoshchild in her classical book titled "The managed heart: commercialisation of human feelings" published in 1983. She captured the deep emotional labour involvement of flight attendants mandated to manage their feelings appropriately by indulging in publicly observable facial and bodily display that portray pleasantness during customer contact (Hochschild, 1983, p. 7). Hochschild further argued that this expectation of friendliness and courtesy in customer service related roles can be translated into 'rules of regulating feelings' (i.e. prescribed standards that guides emotions that should be experienced) and compulsorily expressed during service encounters. In addition, Ashforth and Humphrey (1993, p. 96) claimed that "emotional labour is a double-edged sword" phenomenon in which when its functional capacity is taken into consideration, it is a valuable means of facilitating task effectiveness. For instance, it provides customer service employees with incentives to regulate the dynamic and sometimes unexpected 
nature of interactions with customers and thus allowing the service worker the ability to control conversations with a sense of self-efficacy (Lewig \& Dollard, 2003).

On the other hand, Ashforth and Humphrey (1993) further points out some facets of emotional labour that can be detrimental to service performance and employee well-being. This happens when the customer service agent becomes susceptible to high stress from conflicting experiences occurring between their actual (or real) emotions and the modifications of inner feelings to match required expressions. Hochschild's contention is that such incongruence between feelings that makes the employee cease to recognise or even feel authentic emotions could be inherently dehumanising and mentally disturbing. This is because every opportunity for the worker to gain autonomy over their emotions is taken away and substituted with organisationally desired expectations of emotional enactment (Mann, 2007). Consequently, telephone advisors are typically made subordinates to customers at all times since the nature of service jobs requires the agents to constantly 'smile down the phone' and maintain a polite disposition even in the face of customer hostility (Yagil, Luria, \& Gal, 2008). Therefore, service workers are found to either engage in deep acting or surface displays during service interactions. Surface acting is conceptualised as pretending or faking to have desired emotions while deep acting involves the actual expressions of expected emotions (Hochschild, 1983). Thus, McQueen (2004, p. 104) argued that continuous and intense involvement in emotional labour in satisfying service demands can become stressful and exhausting. Consequently, the intensity of prolonged surface acting may lead to personal and work-related maladjustment such as low self-esteem, mental fatigue and cynicism towards customers been served (Mann, 2007, p. 556). It is therefore suggested that if the consequences of emotional labour is not given priority attention by call centre organisations, numerous opportunities of making it easier or improving HR practices in this direction may continuously yield undesirable service outcomes.

The call centre industry emerged as one of the fastest growing sectors in Nigeria after the National Government decided to deregulate the sector in 2001. This enabled various local and foreign ICT investors the opportunity to engage in mobile phone operations popularly known as Global System for Mobile (GSM) telecommunications wireless business in Nigeria (Adebisi, 2011). With a population of almost 140 million people exiting in Nigeria (Fajana, 2008), the Nigerian mobile telecommunications services was described as one of the fastest growing markets in Africa with 129 million mobile phone subscribers on various networks (Pyramid, 2010). The market is saturated with leading brands such as Mobile Telecommunications Network, (MTN), Nigeria, Globacom, Etisalat, Mtel, Zain, Airtel amongst a host of others. The Nigerian telecoms industry is highly competitive because of the continuous proliferation of various service providers which allows increased consumer switching options. Certainly, the diversification of the Nigerian economy from the oil and gas sector to the telecommunications industry became a pillar for economic growth for the country by the creation of call centre employments and business outlets for the 
distribution of mobile technologies and services. However, it is worth mentioning that Nigeria is still riddled with national challenges facing its political, economic and social status from the apparent leadership failures, high unemployment rates, poor infrastructure and corruption (Ampratwum 2008). These national problems makes Nigeria a stress prone country and consequently, fertile field for the present study.

\section{Methodology}

In collecting data, semi-structured interviews were conducted while an interpretative phenomenological analysis (IPA) was used to gain ideographic insights of participants' lived experiences (Smith \& Osborn, 2003). The IPA method like other naturalistic research methodologies is designed to provide intricate and detailed understanding of how people construct meanings of social realities (Smith, 1996) which is examined through interpretive processes especially where there are no prior research on such research enquiry. The underlying philosophical assumption of following a qualitative paradigm is the belief that peoples' expressed thoughts are more vivid from their verbal accounts as they try and make sense of their world. Thus, a Purposive sampling method was used to recruit the study participants. Access was gained into one of the Nigerian call centre situated in one of the densely populated commercial areas of Lagos state, Nigeria. The participants were selected based on their length of work experience (employed for a minimum of one year), age (25-35 years old), level of education (University undergraduates and graduates). Each of the face-to-face interviews took about 45-60 minutes and was conducted on site subject to prior consent obtained from all participants. Open-ended questions were asked to probe employees' perceptions of the topic while all the interviews were audio-recorded. The questions centred on participants' lay interpretation of what emotional labour demands and consequences of feigning emotions. Given the request for confidentiality and anonymity, pseudonyms were used to represent the names of participants. To begin the analysis, all the interviews were transcribed and afterwards read repeatedly for purposes of making initial notes of points of interest from key descriptive words, comments and phrases from the interviews that were related to the topic under study. This was then followed by coding emerging themes that best captures the essential qualities of the transcribed interviews. The final stage was "translating the themes into a narrative account" (Smith and Osborn, 2003) which then informed the conceptual framework that emerged from findings.

\section{Findings}

Various themes emerged from the interviews that directly addressed the objectives of study. Thus, the analysis visibly engaged in striking an equilibrium between the emic of participants trying to uncover their realities of call centre emotional labour and the etic (the author's effort) to interpret how the participants are trying to 
make sense of the phenomenon being investigated. The emergent themes of how emotional labour practices are conceptualised are as follows.

\subsection{Prioritising feelings}

Some of the participants described emotional labour as a normative organisation of behaviours that suits call centre service. This was interpreted as showing presentable manners that first, keeps the customer impressed and secondly, making sure responses are in accordance with organizationally defined rules and guidelines. They confirmed that these positive behaviours of always expressing emotions such as joy, courtesy and interest in interacting with the customer were said to be formally prescribed irrespective of how the agent felt. One of the interviewees named John who claims to have been employed for two years stated that: "In my opinion, the rules of expression mandates me to be compliant [...] it a norm that I must always sound courteous to customers irrespective of the service pressures"

Another participant called Sarah for the purposes of this study said that: "This is the one of the main aspects of our call centre work which involves a continuous transformation and adjustment of one's expressions".

The above excerpts resonates with some research findings that depicts the climate of control in call centres is based on managing business by a deliberate corporate use of emotional components of display to ensure service is not compromised (Kinnman, 2009). The views of the participants portrays display rules as an 'intra-psychic process' that tilts the interactional balance in favour of the customer (Grandey, Diefendorff, \& Rupp, 2013). These sets of participants interviewed shared the belief that these conformist rules are intended to create a uniformity model that prescribes a congruence between the norms and values of organizations and the behavioural expectations of call handlers (Mann, 2004).

\subsubsection{Productivity gauge}

Majority of shared views $(n=17)$ about the rules of affective display is that these intrinsic expectations are mainly tailored to fulfil the dual objectives of call centre businesses; which is to reduce cost and standardise customer service. In other words, most participants perceived that the reason for emotional regulations was to serve customer and at the same time making sure that agents attend to a large quantity of calls within a prescribed and shortest possible time. An example of this perception was illustrated in the following dialogue with one of the interviewees: "My understanding of emotional management is the way I must consciously compose voice during engagement as well as meeting the customer needs within 5-6 minutes allocated to each call" (Joe, Nigerian call centre agent).

In a similar vein, another participant commented that: 
"Having worked in this call centre for almost three years as a university graduate, I consider managing my emotional disposition during customer interactions as a managerial prerogative that expects me to be fast and flawless at the same time".

The above comments revealed the extent to which most agent believe that an increasingly important aspect of their service role means ability to carefully selfmanage their emotions judiciously and continuously in meeting service targets. In addition, all the agents interviewed contextualise emotional display as an occupational norm that instils a culture of friendliness irrespective of contrary dispositions.

\subsubsection{Brand image}

Interestingly, few of the interviewees $(n=5)$ gave a broader interpretation to emotional labour. While they acknowledged that display rules and expectations at work are in-house practices guiding agent-customer interfaces, its fundamental purposes were suggested to transcend beyond a regulation of automated workflow and service guidelines. These few agents were of the perception that the values placed on affective expressions are for the purposes of corporate brand protection. The agents identified display rules as standardisation of behavioural impressions geared towards operational competitiveness. One of the quotes from the interview states: "I think the necessity of emotional regulation is for purposes of selling services, dealing with customers acceptably, and delivery superior service far above our other competitors so that we can retain our customers who in turn recommend their friends and families to our mobile network".

The agents were also of the viewpoint that the restrictions placed on their emotions are basically for organisational profits which is made possible through IT monitoring systems. Similarly the participants confirmed the adherence to emotional self-management aims to foster delivering of superior services and making sure that customer satisfaction is prioritised as a strategic goal. One of the agents interviewed observed commented thus: "Since I am regarded as one the company's representative to the general public, I must put forward the best attitude and language"

From the participants' perspective, the corporate personality of the company comes before their individualised feelings. Most of the agents further explained that they intrinsically cope (Lazarus \& Folkman, 1984) with negative customers just for the sake of the organisation. Emotional coping belief is associated with most collectivistic national cultures where people prefer to avoid confrontations but believe in yielding and compromising personal rights for the common good of others (e.g. family, work group and society) (Hofstede, 2001). The Nigerian collectivist orientation presents social patterns consisting of loosely knitted individuals (which in this case are call centre agents) that regard themselves as belonging to one or more collectives (e.g. work superiors, organisation and customers) and are motivated by the norms, obligations and duties imposed on them by their employers.

Going further to address the second objective of the present research, the study findings indicated that almost all the agents $(n=16)$ were apt to link the regulatory 
rules of interactions to some level of distorted performance outcomes. Some of the agents pointed out that if careful observations are made about their interpretation and meanings ascribed to emotional labour, it is noticeable that the rules are all aimed at promoting call centre profits irrespective of the detrimental effects of the continuous inhibition of 'true emotions'. Consequently, the following themes emerged from the interviews as some of the negative experiences underpinning some facets of emotional labour in Nigeria.

\subsubsection{Negative affect}

Almost $65 \%$ of participants made reference to the various degrees of emotional friction they experience sometimes during service interactions. Similar to prior studies on the negative impact of emotional regulations in service jobs (see Diefendorff, Croyle, \& Grosserand, 2005; Kinman, 2009; Choi, Cheong, \& Feinberg, 2012), these interviewees confirmed that emotional dissonance was an adversarial phenomenon to productivity. Most of the agents explained that negative affectivity occurs when there is a discrepancy between their real and regulated emotions which invariably results into burnout. Most of these participants confessed how they tolerate difficult customers by engaging in surface acting not really to pacify the customer but just to discharge them as quick as possible. One of the participants said: "Although we are always expected to authentically sound helpful to our customers over the phone, but this is not always possible given the number of calls we deal with [...] sometimes the negative behaviour of some customers just puts you off and I just have to pretend that I am listening to them".

When this is the case, some participants narrated how they feel emotionally drained and lack energy to maintain good composure especially on work days when the call volumes are very high. The participants also made it clear that exhaustion leads them to sometimes behave in a disengaged and pretentious way when their emotional resources are depleted through long staged surface acting.

\subsubsection{Role stress}

A few participants emphasized how obscure their role could become when they are simultaneously required to meet the dual objective of business which is customer satisfaction as well as speed in delivery. One of the narratives of an agent was that: "I am sometimes cut up between two opinions especially when dealing with a contract phone user who is calling in with an elaborate complaint about unfair charges on his monthly subscription [...] some customers will want the problem solved right there and then while they are still on the phone. This may take some time because I would need to go into various system applications to find out what the problem is but my manager sometimes insists on speedy delivery at the same time".

The interview with this agent revealed further that call centre managers will sometimes prefer agents to arrange call backs with excessively demanding customers. 
Two other agents corroborated this story. It was said that call centre managers focus on using technology to hasten customer interactions especially when it is suspected that the 'average speed to answer' is been over-extended beyond regulatory stipulations. Furthermore, some of the interviews also revealed views on how participants experience role stress arising from the lack of clarity on effectively standardising calls to fit the productivity agenda of management. On turnover issues, most participants' shared similar views of their inability to either leave or change jobs considering the tight employment markets existing in Nigeria. For example one narrated that: "I can never think of leaving my job because of the high rate of unemployment in Nigeria [...] I have learnt to endure and ensure I fulfil the minimum service standards to secure my job".

The participants agreed that occupational stress is certainly one of the weaknesses of the Nigerian workplace environment arising from the many national challenges facing the country.

\subsubsection{Work-life conflict}

Interestingly, a number of participants shared concerns on how the effects of emotional labour can potentially spillover into non-work domains and leading to perceived work-family conflicts. The agents $(n=3)$ who were either married or had childcare responsibilities illustrated how the intensiveness of emotional labour regulations adversely impact their work-life interface leading to strained-based conflicts (Greenhaus \& Beutell, 1985). One of the advisors who is married and claimed to have two young children commented that: "The most difficult customers to deal with are the non-English speaking customers passed through on our language line [...] they won't listen to you and could turn abusive [...] I think sometimes I unconsciously transfer some office agitations to my family members at home especially my children when I am stressed".

Other agents with families also shared similar sentiments of how strain-based causes conflict between their work and family domains manifest through symptoms of irritability, exhaustion, anxiety and bad mood that can potentially cause social withdrawal from family, religious or leisure activities. This happens when energies required to attend to the family (especially having fun with their children) is almost nonexistent due to resource drain at work.

In general, when the participants were asked what forms of practices would be suitable in extenuating some of these negative consequences of emotional labour mentioned, almost half of them suggested managerial practices that endorses power sharing and control systems between team managers and service agents was perceived as a potential moderator of the dire consequences of emotional labour. There were claims that call centre managers should give room to agents to use their discretion to make day-to-day decisions on service calls. Empowerment of this nature allows the service worker to make informed decisions on how best to handle each call with little or no encumbrance from monitoring processes. Some of the interviewees 
frowned at the production-line approach where the organisation seeks to entirely control service system that leaves nothing to the discretion of the employee. In general, some participants maintained a candid view that high levels of call monitoring can be lessened especially for the experienced and top performing agents. This is because they have already developed a sense of accountability, responsibility and authority on dealing with a wide range of customer expectations.

In addition, some participants mentioned the need for more social support from bottom-line managers and the organisation. It was identified that quality social support is lacking in the Nigerian call centres as managers are more concerned about profitability agendas through hard selling of products and services. Agents desired more forums for "de-stressing", such as increasing team briefings and one-to-one meetings, where they can freely express their concerns in such a way of defusing them. One agent remarked that "I will desire our call monitoring feedbacks to be used as training periods and improvement forums rather than a mere routinized session with our line managers". Some agents also claimed that dismantling the rigidity of only seeking managerial support and allowing experienced service colleagues to help the weak ones may also go a long way in getting quicker results especially when team leaders are also overwhelmed with managerial demands.

A handful of participants complained of career stagnation considering the high compliance to emotional regulations, work scheduling and low skilled nature of call centre work that suggest career prospects and promotional opportunities may not be a major feature of this sector (Houlihan, 2000). Interestingly, eight of the participants in their separate interviews shared similar views of the importance of providing all service employees with continuous personal development chances for purposes of increasing their interpersonal skills. Agents confirmed that education is needed on how to maintain and retain psychological resources during service encounters. One of the agents' highlighted how short and educative professional development sessions can improve job capabilities, knowledge and boost self-confidence. Other developmental needs such as listening in to calls that meet the quality criteria and managerial training on how to use the performance monitoring for mentorship and coaching avenues rather than punitive measures were also deemed appropriate.

\section{Discussion}

This study provides empirical evidence on emotional labour practices and outcomes in the Nigerian call centre context. Evidently, the results on emotional labour realities in Nigeria was not entirely different from those of other previous researches conducted in the West (e.g. Wege Dick, \& Bernstorff, 2006; Mann, 2007; Kinman, 2009). This affirms the similitude of call centre job design and management systems irrespective of location. Like previous research findings, evidence was provided on how call centre employees engage in emotional regulations during customer interactions in Nigeria. However, apart from the limited research on the impact of emotional labour regulations on service employees working in call centres situated in non-Western 
context, one gap that this current study sought to address was that most emotional research often concentrates on perceived outcomes and organisational factors influencing affective deliveries without initially finding out what interpretations and meaning service workers hold about emotional labour. Research evaluating personal definition of emotional labour in customer service roles are rarely gathered from interpretative perspectives.

Hence, the study revealed various themes emerging from the participants conceptualising that this self-regulatory rules are fashioned to prioritise service behaviours, gauge productivity levels as well as brand image protection. It is clearly deducible from the interviews that expectations of emotional compliance are primarily designed for organisational performance. Thus, Dean and Rainnie (2009, p. 326) argued that customisation and standardisation of employee emotions to meet the insatiable expectations of customer needs and business gains are often prioritised far above employee training on affective consistency and productive abilities to cater for the mass market they encounter on a daily basis. These are some of the obvious reasons why Nigerian agents reiterated that the intensity of emotional work results in emotional dissonance which is commonly known as a salient strain phenomenon in call centre employments. In addition, the sample of service workers in the present research expressed how verbal customer aggression could be a formidable work stressor that is strongly associated with burnout.

Similar to other call centre studies, the participants emphasized how high emotional service restrictions contribute to role stress (especially role conflicts and ambiguity). Role conflict and role ambiguity as occupational stressors are well-known to extenuate an individual's abilities to perform by diverting capabilities and competences away from job performance towards coping with these role stressors. It is assumed that personal resources available to the employees are limited (e.g. time, energy, effort and skill) and needs to be appropriately apportioned across role tasks. Tuten and Neidermeyer (2004, p. 27) further established that the presence of conflict and ambiguity as stressors drains an employee's capabilities to satisfy job demands. Going further, the findings revealed that the collectivistic nature of the Nigerian culture makes participants more inclined to appropriate emotionally focused coping approaches which refers to one's tendency to manage painful emotional reactions in a temperate manner especially when such conflicting challenges cannot be altered or changed momentarily (Herman-Stahl, Stemmier, \& Petersen, 1995). This could involve avoidance, distancing or accommodating such adverse conditions. Although it is found that adopting a problem-focused strategy inform of re-designing intrinsic work characteristics, increasing locus of control and providing social support to call centre employees will produce better service outcomes (Tsai \& Huang, 2002). In addition, the existing research unfolded the degree to which emotional work can have negative implications on role expectations that extends beyond the context of work. For some of these employees, the perception of volitional rules of display was a key predictor of work-family conflict. Shared views showed how the transition (border-crossing) of 
negative emotions from work diminishes satisfactory involvement in family life (Clark, 2000).

From the foregoing, this study confirms the ubiquitous perceptions of the detrimental nature of the various components of emotional labour that seems to far outweigh its importance in call centre work. This is because emotional labour practices are mostly organisationally-centred more than user friendly rules of engagement. Therefore, the participants suggested three moderating factors (i.e. empowerment, social support and professional development) as fit practices necessary for creating an employee-job fit situation presented in figure 1 below. These facilitative agendas can potentially bridge the gap between the perceptions of the rigidity of display rules and its negative consequences.

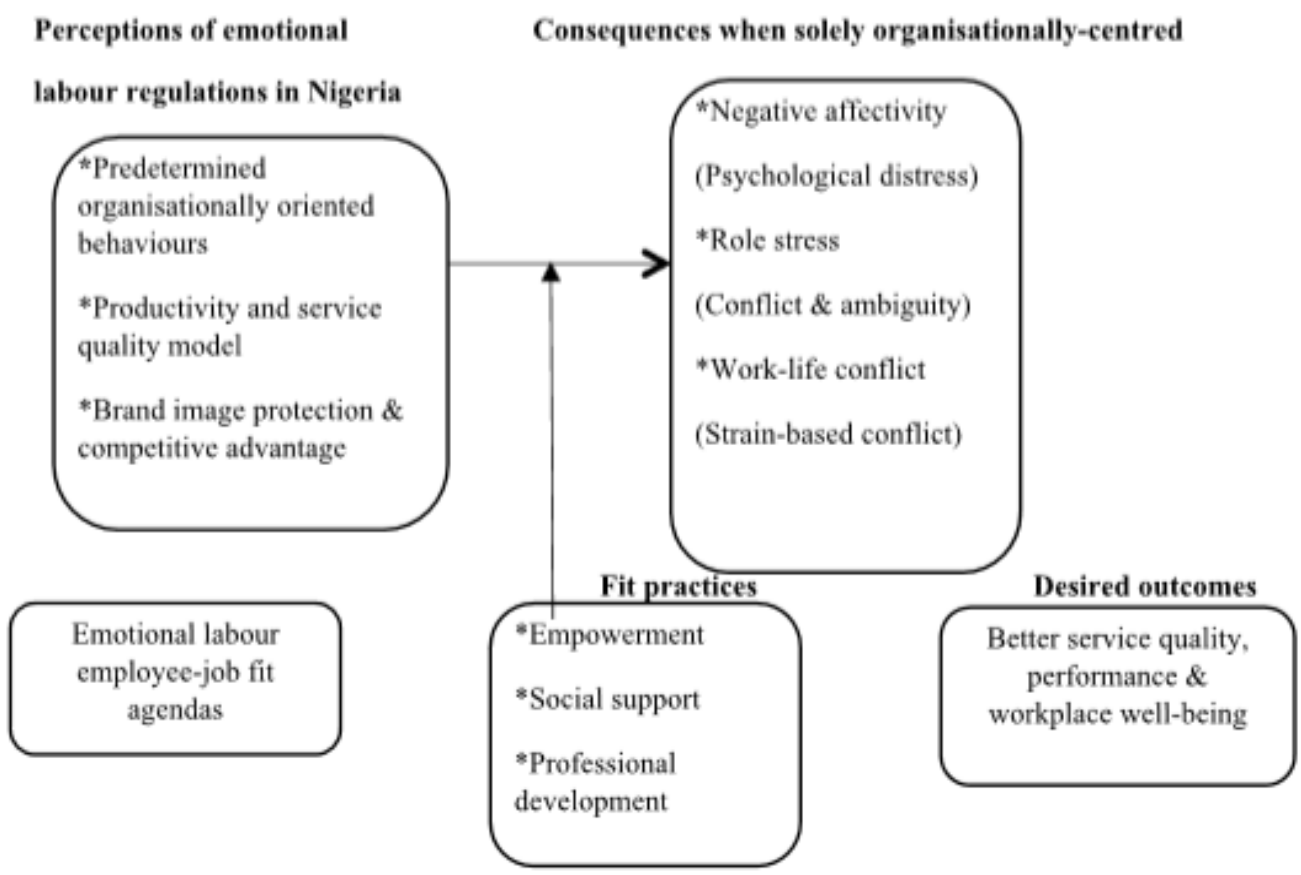

\section{Figure 1: The author's proposed framework of study for future development and} testing

The proposed framework (figure 1) that summarises the entire study findings was conceptualised for future development and empirical testing either on a wider scope involving more call centres within the Nigerian telecommunications industry or other service industry context other than call centres. Figure 1 thus depicts the themes that emerged from the qualitative accounts of study. Further, the participants felt that the adverse consequences of these rules such as negative affect, role stress and work-life conflict can be altered by providing employee empowerment, social support 
and professional developmental needs. For instance, the 'fit practices' emerging from the study as necessary HR policies needed to derive desired outcomes from affective deliveries bears close resemblance to Schneider, White and Paul (1998)'s fundamental HR issues and Boruucki and Burke's (1999) primary employee concerns within a sales and service environment. These concerns arise when service employees feel they are being used as "the company's main shock absorbers" with little or no attempt by the company to either improve their job performance or replenish drained psychological resources. But since call centre organisations expect customer service agents to adhere to seamless emotional labour practices, then it behoves such frontline organisations to provide employees with the necessary tools to achieve this objective as proposed in the study framework.

\section{Conclusion}

In conclusion, this study justifies the notion that emotional work is integral to call centre labour of which Kinman (2009, p. 130) suggested "that its performance is related to a variety of strain outcomes". As proposed in the conceptual framework of this research (see figure 1), Kinman (2009) commented that "in order to enhance employee wellbeing and job satisfaction, it is necessary for organisations to recognise these risk (i.e. negative outcomes) and implement interventions to help employees manage their emotions more effectively". Ackfeldt and Malhotra (2013) suggested that managerial interventions in form of employee empowerment (power sharing), training and development could assist managers combat role stress challenges and other detrimental consequences of emotional work. This is very much relevant to the Nigerian situation. Managers should allow employees a higher degree of external locus of control over emotional labour processes. Thus, making service agents take responsibility for monitoring their own personal performance can serve as key moderator of psychological stress that is also associated with work-life conflict. Call centre managers should acknowledge the fact that work-life balance is an important aspect for an employee's psychological well-being and performance output.

One of the main limitations of the study arises from the qualitative approach used for collecting and analysing of data. Thus, biases that can potentially contaminate findings cannot be overruled. More so, the research was based on only one call centre which makes the study findings highly subjective. However, the study produced an insightful framework which may be tested quantitatively for external validity and generalisation purposes. Overall, the findings present areas for further research such as cross examining interviews of service agents with managerial perceptions of some challenges that middle management employees also face as 'implementers' of emotional labour practices and policies. This may uncover more robust solutions that can further provide the right balanced interventions for improving customerorganisational interfaces. 


\section{References}

Adebisi, S. (2011), GSM marketing services providers operations and customer satisfaction in Nigeria: An empirical Investigation. Acta Universitatis Danubius .Economica, Vol. 7 No.1, pp. 1-20.

Ackfeldt, A., Malhotra, N., (2013), Revisting the role stress-commitment relationship: Can managerial interventions help? European Journal of Marketing, Vol. 47 No.3, pp. 1-37.

Ampratwum, E. F. (2008), The fight against corruption and its implications for development in developing and transition economies. Journal of Money Laundering Control, Vol. 11 No.1, pp. 76-87.

Ashforth, B. E., Humphrey, R. H. (1993), Emotional labour in service roles: The influence of identity. Academy of Management Review, Vol. 18, pp. 88-115.

Choi, S., Cheong, K., Feinberg, R. A. (2012), Moderating effects of supervisor support, monetary rewards, and career paths on the relationship between burnout and turnover intentions in the context of call centre. Managing Service Quality, Vol. 22 No. 5, pp. 492-516.

Clark, S. C. (2000), Work-family border theory: a new theory of work-family balance. Human Relations, Vol.53, pp. 747-70.

Das, D., Dhawadkar, R., Brandes, P. (2008), The importance of being `Indian': Identity centrality and work outcomes in an off-shored call centre in India. Human Relations, Vol. 61 No.11, pp. 1499-1530.

Dean, A. M., Rainnie, A. (2009), Frontline employees' views on organisational factors that affect the delivery of service quality in call centres. Journal of Services Marketing, Vol. 23 No.5, pp. 326-337.

Diefendorff, J. M., Croyle, M. H., Grosserand, R. H. (2005), The dimensionality and antecedents of emotional labour strategies. Journal of Vocational Behaviour, Vol. 66 No.2, pp. 33957.

Fajana, S. (2008), The Nigerian informal economy: Instigating decent work and pay, and national development through unionisation. Employee Relations, Vol. 30 No.4, pp. 372-390.

Grandey, A. A., Diefendorff, J. M., Rupp, D. E. (2013), Emotional labour in the 21st century: Diverse perspective on emotion regulation at work. New York: Psychology Press, Routledge.

Greenhaus, J. H., Beutell, N. J. (1985), Sources of conflict between work and family roles. Academy of Management Review, Vol.10, pp. 76-88.

Herman-Stahl, M. A., Stemmier, M., Petersen, A. C. (1995), Approach and avoidant coping: Implications for adolescent mental health. Journal of Youth and Adolescence, Vol. 24 No 6, pp. 649.

Hochschild, A. (1983), The Managed Heart, University of California Press, Berkeley, CA.

Hofstede, G. (2001), Cultures' consequences: International differences in work-related values, (2edn), London: Sage Publications.

Houlihan, M. (2000), Eyes wide shut? Querying the depth of call centre learning. Journal of European Industrial Training, Vol. 24 No. 2, pp. 228-240.

Jaarsveld, D., Poster, W. R. (2013), Emotional labour over the phone. In Grandey, A. A. Diefendorff, J. M. and Rupp, D. E. (Eds.), Emotional labour in the 21st century: Diverse perspectives on emotion regulation at work. New York, NY: Psychology Press, Routledge.

Kinman, G. (2009), Emotional labour and strain in frontline service employees: Does mode of delivery matter? Journal of Managerial Psychology, Vol. 24 No. 2, pp. 118-135. 
Lam, W., Chen, Z. (2012), When I put on my service mask: determinants and outcomes of emotional labour among hotel service providers according to affective event theory. International Journal of Hospitality Management, Vol. 31 No.1, pp. 3-11.

Lazarus, R. S., Folkman, S. (1984), Stress: Appraisal and coping. New York: Springer.

Lewig, K. A., Dollard, M. F. (2003), Emotional dissonance, emotional exhaustion and job satisfaction in call centre workers. European Journal of Work and Organizational Psychology, Vol. 12, pp. 366-392.

Mahesh, V. S., Kasturi, A. (2006), Improving call centre agent performance: a UK-India study based on the agents' points of view, International Journal Service Industry Management, Vol. 17 Iss: 2, pp. 99-113.

Mann, S. (2004), People work: emotion management, stress and coping, British Guidance and Counselling, Vol. 32 No.2, pp. 204-21.

Mann, S. (2007), Expectations of emotional display in the workplace: An American/British comparative study. Leadership and Organisation Development Journal, Vol. 28 No.6, pp. 552-570.

McQueen, A. (2004), Emotional intelligence in nursing work. Journal of Advanced Nursing, Vol. 47 No.1, pp. 154-62.

Morris, J.A., Feldman, D.C. (1996), The dimensions, antecedents, and consequences of emotional labour, Academy of Management Review, Vol. 21 No.4, pp. 986-1010.

Pyramid research on the impact of mobile services in Nigeria, (2010) accessed August, 2015 available online at www.pyramidresearch.com.

Schneider, B., White, S. S., Paul, M. C. (1998), Linking service climate and customer perceptions of service quality: testing a casual model. Journal of Applied Psychology, Vol. 83 No. 2, pp. 150-63.

Smith, J.A. (1996), Beyond the divide between cognition and discourse: using interpretative phenomenological analysis in health psychology. Psychology and Health, Vol.11, pp. 261-71.

Smith, J. A., Osborn, M. (2003), Interpretative phenomenological analysis, in Smith, J. A. (Ed.), Qualitative Psychology: A practical guide to research methods, Sage Publications, London, pp. 51-80.

Tsai, W., Huang, Y. (2002), Mechanisms linking employee affectivity delivery and customer behaviour intentions. Journal of Applied Psychology, 87(5), 1001-8.

Tuten, T. L., Neidermeyer, P. E. (2004), Performance, satisfaction and turnover in call centres: The effects of stress and optimism. Journal of Business Research, Vol. 57, pp. 26-34.

Wegge, J, Dick, R, V., Bernstorff, C. (2010), Emotional dissonance in call centre work. Journal of Managerial Psychology, Vol. 25 No. 6, pp. 569-619.

Yagil, D., Luria, G., Gal, I. (2008), Stressors and resources in customer service roes: Exploring the relationship between core self-evaluation and burnout. International Journal of Service Management, Vol. 19 No. 5, pp. 575-593. 